\title{
WHAT'S THE USE OF FACTOR CONTENTS?
}

Edward E. Leamer

Working Paper 5448

\author{
NATIONAL BUREAU OF ECONOMIC RESEARCH \\ 1050 Massachusetts Avenue \\ Cambridge, MA 02138 \\ February 1996
}

Supported by NSF grant SBR-940911. This paper is part of NBER's research program in International Trade and Investment. Any opinions expressed are those of the author and not those of the National Bureau of Economic Research.

(C) 1996 by Edward E. Leamer. All rights reserved. Short sections of text, not to exceed two paragraphs, may be quoted without explicit permission provided that full credit, including $\odot$ notice, is given to the source. 


\title{
WHAT'S THE USE OF FACTOR CONTENTS?
}

\begin{abstract}
The net imports of labor embodied in international trade has been a fairly small and stable share of the US labor force. From this some conclude that trade has not been a major contributor to the income inequality trends. This is a non sequitur. The labor embodied in trade is jointly determined by tastes, technologies, factor supplies and the external goods market. Although it is impossible to use factor contents to disentangle trade from technology, the factor contents can be used to suggest the change of earnings shares if the country were to close down external trade entirely. However, this is a proper application of factor contents only if tastes and technologies are log-linear, if trade is balanced and if foreign input intensities are used to compute factor contents of non-competing imports. Factor contents are virtually useless if technologies and tastes are not log-linear, or if the external deficit is substantial and variable. Factor contents do not tell us anything about earnings levels as opposed to shares. They also do not inform us of the impact of partial trade barriers that change relative product prices but do not completely eliminate trade. In other words, the title question is rhetorical.
\end{abstract}

Edward E. Leamer

Anderson Graduate School of Management

University of California

Box 951481

Los Angeles, CA 90095-1481

and NBER 


\title{
What's the Use of Factor Contents? ${ }^{1}$
}

\author{
Edward E. Leamer \\ Anderson Graduate School of Management \\ UCLA \\ Los Angeles, CA 90024 \\ (310) 206-1452 \\ FAX: (310) 206-2002 \\ January 19, 1996
}

Calculation of the factor content of international trade has a long intellectual history dating from Leontief's (1954) discovery that US imports in 1947 were more capital intensive than US exports. This seemed so incompatible with the clear capital abundance of the US that the finding earned the name "The Leontief Paradox". The profession seemed to miss the message of the label, and acted as if it were "The Leontief Decisive Contradiction," the first of many knock-out blows apparently rained down upon the Heckscher-Ohlin model. But Leamer(1980) showed that Leontief's finding was only a paradox, not a contradiction. It turns out that a carefully formulated but entirely standard Heckscher-Ohlin model allows a capital abundant country to have imports more capital intensive than exports. Indeed if one does the calculation right, Leontief's 1947 trade data reveal the US to have been more abundant in capital than labor, not the other way round.

Many economists are now using the factor content calculations to try to determine if international commerce is a source of increasing income inequality in the United States. Like Leontief, many do so without reference to any explicit model that can justify their inferences. From the fact that these factor contents are generally small and stable shares of US labor supplies, these economists conclude that international trade has not had much impact on US wages. For example, Katz and Murphy (1992) report

"To estimate the labor supply equivalents of trade, we transform trade flows into equivalent bodies on the basis of the utilization of labor inputs in the domestic manufacturing industries that constitute the bulk of the traded goods sector. We do this by estimating the direct labor supply embodied in trade, ignoring indirect input-output effects." ( $p$ 63)

"Table VII presents the changes in relative labor demand predicted by changes in international trade in manufactures. The table indicates that the effects on relative labor demands of trade were quite moderate until substantial deficits developed in the 1980s. The adverse effects of trade on relative labor demand are concentrated on high school dropouts." ( $p$ 65)

"Demand shifts arising from changes in international change in manufacturing only start to be of quantitative significance with the appearance of large trade deficits in the 1980s." (p77)

\footnotetext{
' Supported by NSF grant SBR-940911.
} 
Krugman and Lawrence(1993, p. 15) have a similar opinion regarding the usefulness of factor contents:

"It is possible to reach the same conclusion by another route. Recent work by Lawrence Katz and others has calculated the skilled and unskilled "embodied" in US trade -- that is the labor inputs that were used to produce exports, and that would have been used to produce our imports if they had been made domestically. If the increase in US exports had embodied considerably more skilled and less unskilled labor than the increase in imports, this would have reduced the relative demand for less-educated workers. (This embodiment approach is not quite equivalent to the Stolper-Samuelson approach described above, but may be viewed as a close approximation.) In fact, however, the net embodied labor flows are small."

This is echoed by Krugman(1995, p.36)

"But the general idea that it is useful to estimate the factor content of trade is vindicated. And so is the point that since the changes in 'effective' factor supplies associated with measured trade volumes are small compared with either actual changes in these supplies or the apparent changes in factor demand due to biased technological change, trade is unlikely to be the main force driving wages."

Like Leontief's paradox, these claims have a ring of truth to them, but they need to be backed up with some clear theoretical structure. Viewed from the perspective of the traditional Heckscher-Ohlin general equilibrium model this use of the factor contents is suspicious since there is no necessary relationship between factor contents and the response of local labor markets to changes in the external product markets. There are several reasons why the link between factor contents and wages is ambiguous. First and foremost is the fact that factor content of trade is the realized excess demand for the factor. This excess demand is jointly determined by internal and external tastes, technology, and factor supplies. Changes in the factor content of trade can therefore be attributed to globalization only if there are no coincident internal changes in tastes, technology or factor supplies. For example, technological change may have lowered the internal demand for unskilled workers at the same time that the global external goods market was lowering the implicit price of these workers. These two forces work in opposite directions and may keep the labor embodied in trade small even though the implicit external price of unskilled workers falls substantially. Likewise an increase in the internal supply of unskilled workers caused by educational failures or a migrant inflow will lower the net external labor demand and will keep the factor content figures small. Absent the migrant inflow or the educational failures, the wage rate could have been exactly the same, yet the factor contents would have been entirely different. Thus one cannot connect changes in factor contents with globalization of product markets.

This is very clear in the simple supply and demand diagrams, Figures 1 and 2. Figure 1 has the internal labor demand and labor supply schedules and also the infinitely elastic external labor supply. ${ }^{2}$ The

\footnotetext{
${ }^{2}$ There are three equivalent ways of expressing the factor price equalization theorem applicable to a small open economy: (a) the GDP function is linear in the factors, (b) marginal productivities don't depend on
} 
externally determined wage rate selects an internal excess demand, which is the factor content of trade, appropriately labeled in Figure 1. In Figure 2, the external marketplace is dictating a lower wage rate at the same time that the internal demand has shifted downward. These two shifts together leave the factor content unchanged. From this unchanging factor content it does not follow that "globalization" is unimportant. On the contrary, the falling wage level is entirely due to the globalization effect since wages are completely determined by the infinitely elastic external labor supply.
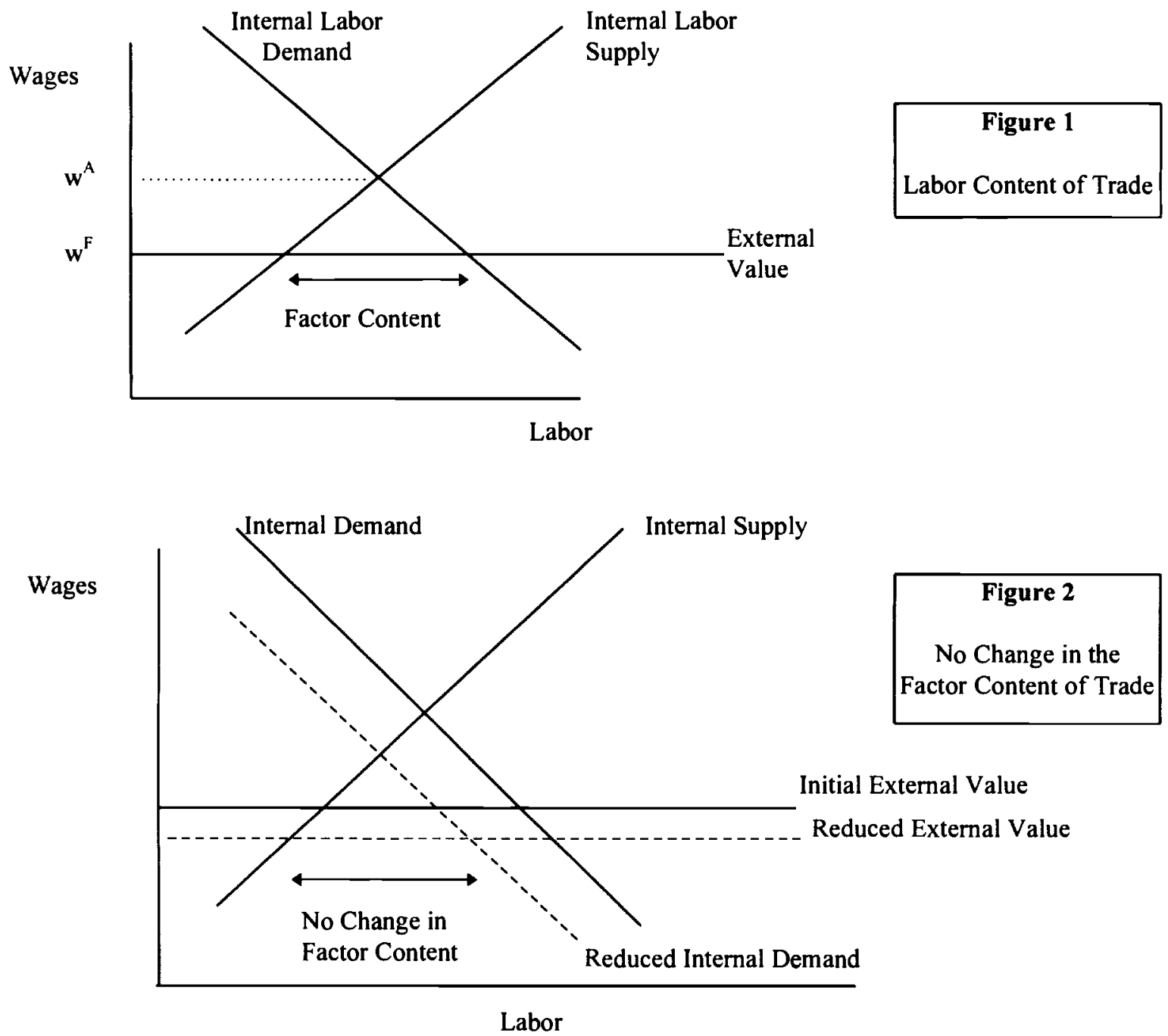

Nevermind, one may reply, factor contents are not about separating technology from trade. Factor contents are about the impact of trade barriers. According to this line of thinking, the net trade in factor services is equivalent to a change in factor supplies in a closed economy. If the import of labor services is small in comparison with internal labor supply, it must mean that trade barriers will not much affect wages, unless the elasticity of labor demand is very low. For example, Bowen, Leamer and Sveikauskus(1987) report that in 1967 the US net import of labor services was only about .25\% of US employment. Such a 
small number might be interpreted to mean that economic isolation would have had only a small effect on the compensation of labor. Indeed this seems clear from Figure 1 which contains the free trade wage level $w^{F}$ and the autarchic wage level $w^{A}$. These cannot be much different if the factor content is small, appropriately measured, and depending on the autarchic elasticities of supply and demand for labor.

This argument has a degree of validity to it, but it also needs to be made with care. Deardorff and Staiger (1988) report two basic Heckscher-Ohlin results that link factor earnings with factor contents, subject to two important qualifications. First of all, both results implicitly presume knowledge of the factor content of trade under two equilibria that have the same tastes, technologies, and factor supplies, and that differ only in terms of the external trading opportunities. The most natural application of these results is to predict the impact of prohibitive trade barriers on factor earnings since the factor contents of the current equilibria are directly computable and the factor contents with prohibitive trade barriers are zero. These results usefully apply to factor contents computed for the same economy at two points in time only if tastes, technologies and factor supplies have not changed. The second important qualification is that both results apply to fully diversified equilibria in which all tradables are produced. Noncompeting imports are not allowed. ${ }^{3}$ These results therefore assume away the most important method of isolating a country from the adverse effects on income inequality of trade with low-wage competitors, namely product upgrading.

Deardorff and Staiger's first result describes a fictional ${ }^{4}$ log-linear economy in which earnings shares are fixed technologically. Generally, if there are three or more factors of production, say capital, labor and land, the net trade in labor services may be zero while the country trades capital for land. Then opting for economic isolation can affect wages, just as holding fixed labor but altering the supplies of land and capital can affect the wage rate in a closed economy. For example, in the Bowen, Leamer and Sveikauskus (1987) calculation, the net export of the services of arable land was $19 \%$ of the US supply in 1967. The net import of the services of forest land was $23 \%$ of the US labor supply. If the US opted for economic isolation, and chose not to trade arable land for forest land, it is possible for the compensation of labor to be affected even though imports of labor were only $0.25 \%$ of US supply. It depends on the economy-wide substitutability of labor with the different types of land. ${ }^{5}$ A log-linear economy is different in a rather exceptional way. In such an economy, the share of total labor in GNP is fixed and has to be divided proportionately between domestic labor and the net imports of foreign labor embodied in products (the factor content of trade). If, for example, imports of labor services raise the effective labor supply by $10 \%$, then the wage level relative to GNP must be reduced $10 \%$ to keep labor's share of GNP constant equal to its autarchic level. A complicating factor is that part of the reduction in the ratio of wages to GNP will come from a higher level of GNP afforded by the external trading opportunities. Indeed GNP can

below is materially affected if the country is allowed to have power in the goods market.

${ }^{3}$ For a Cobb-Douglas economy, as discussed below, the result applies even if there are noncompeting imports.

${ }^{4}$ Of course all models are fictional, but some more than others.

${ }^{5}$ As will be shown below, a Cobb-Douglas economy, with constant earnings shares, has a simple univariate relationship between factor contents and the difference between open-economy and autarchic earnings shares. Even with that assumption there is a difference between partial and complete isolation. Complete isolation may leave earnings unchanged but raising partial barriers may nonetheless have an effect. 
increase by more than $10 \%$ thus allowing wages to be higher with trade even though there are net imports of the services of foreign laborers. Although differences in GNP thus make this result uninformative for a comparison of absolute compensation levels, the result can be used to discuss relative levels, e.g. income inequality. If, for example, the factor import of skilled labor services is $5 \%$ of supply while unskilled is $10 \%$, then prohibitive trade barriers would reduce the wage differential between skilled and unskilled workers by $5 \%$.

The second, more general revealed-preference result presented in Deardorff and Staiger(1988) connecting factor price changes and factor supply changes (or factor contents) can be written as ${ }^{6}$

$$
\sum\left(s_{k}^{1}-s_{k}^{2}\right)\left(F_{k}^{1}-F_{k}^{2}\right) / v_{k} \geq 0
$$

where $s$ is the earnings share of GNP, $F$ is the net exports of factors embodied in trade (the factor content), $\mathrm{v}$ is the factor supply, and the superscripts 1 and 2 indicate two different economies with the same tastes, technologies but different external trading opportunities. Just as in the log-linear case, this inequality deals with shares, not absolute compensation levels. This condition means that, generally speaking, factors experiencing increases in supply as a consequence of trade suffer from reductions in their earnings shares. But this inequality is so weak that it renders factor content calculations virtually valueless. In particular, the inequality allows the greatest freedom for wage changes in the factors experiencing the smallest change in supply, the very opposite of the claims in the quotations above.

A third and even weaker result is that the factor content acts like an increase in factor supplies in a closed economy. Formally this is expressed as

$$
\mathbf{w} / G N P=f(v-F ; p, t)
$$

meaning that compensation rates $\mathbf{w}$ divided by GNP are a function of factor supplies $\mathbf{v}$ minus the net export of factor services embodied in trade, $\mathbf{F}$. In this relationship prices $\mathbf{p}$ and technology $\mathbf{t}$ are held fixed. This is the formal characterization of the equilibria depicted in Figures 1 and 2 . But be careful to note that the function $f$ describes the autarchic factor demands: $w / G N P=f(v ; p, t)$, not the open-economy factor demands. The elasticities implicit in the function $f$ are therefore autarchic elasticities, which are smaller than the elasticities of an open-economy, and which can be inferred only indirectly, and thus suspiciously from real data since the US has not been a closed economy.

Finally, Figures 1 and 2 implicitly assume that the internal labor demand and supply functions are the same for a closed economy as for an open one. This is unlikely to be the case. One reason is that trade need not be balanced. Suppose for example that the country in autarchy happens to have the same prices for goods as are dictated by the world general equilibrium. Then with balanced trade there is no trade. If the country runs a deficit, however, it will import the services of labor and other factors as well. But nonzero values for these factor contents don't mean that wages are affected by openness. On the contrary, wages would be exactly the same whether or not there is an external deficit. In terms of Figures 1 and 2 ,

\footnotetext{
${ }^{6}$ The Deardorff-Staiger result is $\sum_{i}\left(w_{k}^{1}-w_{k}^{2}\right)\left(F_{i}^{1}-F_{i}^{2}\right) \leq 0$ with the assumption that GNP's are normalized to equal 1 .
} 
an external deficit increases the internal demand for labor but leaves the compensation rate completely unchanged.

A less obvious reason why labor demand for an open economy is different from labor demand for a closed economy is that trade may entail extreme specialization patterns that would not be chosen by a closed economy, and when this happens product market arbitrage may not be enough to equalize wage rates internally and externally. For example, the US may specialize in capital intensive goods and import labor intensive goods from low-wage countries. This creates a kind of dual labor market in which the imported labor services do not compete for the same jobs with local labor supply. Lower prices for the labor intensive goods may mean more imports of these goods and thus increases in the measured imports of labor services but this need not have any effect on US wages. The treatment of noncompeting imports is a key feature of the work by Adrian Wood (1994), but his calculations do not allow generally for this duallabor market possibility. More on this below.

\section{Conclusion:}

If the imports of labor services embodied in goods is a small share of domestic labor supply, then prohibitive trade barriers would not much affect labor share of GDP if and only if all of the following conditions apply:

(1) Production functions and utility functions are log-linear.

(2) Trade is balanced.

(3) Foreign input intensities are used to compute factor contents of non-competing imports.

The factor content calculations do not inform us about:

(1) The relative effects of technological change and globalization on the labor markets

(2) The effects of complete isolation on labor real earnings (as opposed to labor's share).

(3) The impact of trade barriers which do not completely isolate the country.

In a Heckscher-Ohlin Stolper-Samuelson framework it is prices of tradables and only prices of tradables that carry the news of changes in the international product markets. The factor contents can at best serve as proxies for the relevant price changes. Under some very special and highly unlikely conditions factor contents can be good proxies for the price changes But this amounts to the flimsiest justification of the purposes to which the factor contents are currently being put. This observation more politely and less pointedly has been made by trade economists in many places including Leamer(1993, 1994, 1995), Deardorff and Hakura(1993), Bhagwati(1995), and Baldwin(1995). 


\section{I.0 FACTOR CONTENT ALGEBRA: GENERAL MODEL}

This section reports the most general Heckscher-Ohlin model and point outs the basic difficulties that must arise in linking factor contents with wages. The next two sections discuss special cases with Cobb-Douglas log-linear production functions and utility functions, and also Leontief fixed input technologies.

The variables of a Heckscher-Ohlin model are

$$
\begin{aligned}
& \mathbf{p}=\text { vector of product prices } \\
& \mathbf{w}=\text { vector of factor prices } \\
& \mathbf{A}=\text { matrix of input intensities (inputs per unit of output) } \\
& \mathbf{q}=\text { vector of outputs } \\
& \mathbf{v}=\text { vector of inputs (factors of production) } \\
& \mathbf{t}=\text { technology } \\
& \mathbf{c}=\text { vector of consumption of tradables } \\
& \mathbf{y}=\mathbf{p} \mathbf{c}=\text { total expenditures } \\
& \text { GDP }=\mathbf{w}^{\prime} \mathbf{v}=\mathbf{p}^{\prime} \mathbf{q} \\
& D=\text { deficit ratio }=y / \text { GDP } \\
& \mathbf{T}=\text { trade }=\mathbf{q}-\mathbf{c} \\
& \text { F }=\text { Net export of factor services embodied in commodity trade }
\end{aligned}
$$

The first two building blocks of the production side of the model are

a) Constant returns to scale and cost minimization. From these are derived input intensities that depend on the factor prices $w$ and the technology $t$ but not on the scale of output.

$$
\mathbf{A}=\mathbf{A}(\mathbf{w}, \mathrm{t}) \text {. }
$$

b) Factor market equilibrium conditions equating factor demand with factor supplies

$$
\mathbf{A q}=\mathbf{v} .
$$

From the factor market equilibrium condition we can solve for the factor content of trade as

$$
\mathbf{A}_{\mathrm{T}} \mathbf{T}=\mathbf{A}_{\mathrm{T}} \mathbf{q}_{\mathrm{T}}-\mathbf{A}_{\mathrm{T}} \mathbf{c}_{\mathrm{T}}=\mathbf{v}_{\mathrm{T}}-\mathbf{A}_{\mathrm{T}} \mathbf{c}_{\mathrm{T}}
$$

where the $T$ subscript refers to traded goods.

This equation establishes the first problem: factor contents depend on everything, not just the externally determined prices of goods. The factor content $\mathbf{A}_{\mathrm{T}} \mathbf{T}$ depends on (a) the factors supplied to the tradables sector $\mathbf{v}_{\mathrm{T}}$, (b) the consumption of tradables $\mathbf{c}_{\mathrm{T}}$ and (c) the matrix of input intensities $\mathbf{A}_{\mathrm{T}}$ which is an explicit function of technology $t$ and the factor prices $w$. "Globalization" which takes the form of changes in prices of tradables might alter the supply of factors to the tradables sector $\mathbf{v}_{\mathrm{T}}$, or the consumption of tradables $\mathbf{c}_{\mathrm{T}}$, or the matrix of input intensities $\mathbf{A}_{\mathrm{T}}$. But changes in tastes, in technology or in factor supplies can also alter the factor content of trade. It is thus inappropriate to try to disentangle external from internal causes of increased income inequality by treating the factor content as an indicator exclusively of the external events. One might as well take the factor contents to be indicators exclusively of changes in technology.

Even if technology, tastes and factor supplies are constant and the only thing that is changing is externally determined prices of tradables, there is still a problem. The connection between factor 
contents and factor prices is not at all transparent. Factor price determination comes from the third building block of the production side of the model:

c) Zero profit inequalities that equate product prices to the costs of the inputs for goods that are produced and that set costs exceeding prices for goods that are not produced.

$$
\mathbf{A}_{1 \mathrm{~T}} \mathbf{w}^{\mathbf{w}}=\mathbf{p}_{1 \mathrm{~T}}, \mathbf{A}_{2 \mathrm{~T}}{ }^{\prime} \mathbf{w}>\mathrm{p}_{2}, \quad \mathbf{A}_{\mathrm{NT}}{ }^{\prime} \mathbf{w}=\mathbf{p}_{\mathrm{NT}},
$$

where the subscripts 1 and 2 refer to produced and unproduced tradables and $\mathrm{N}$ refers to nontradables.

A necessary condition for the invertibility of the system of equations $\mathbf{A}_{\mathrm{IT}}{ }^{\prime} \mathbf{w}=\mathbf{p}_{\mathrm{IT}}$, is that the number of produced tradables is not less than the number of factors. If the system is invertible, external competitiveness completely determines internal factor prices according to the Stolper-Samuelson function that maps prices of tradables into factor prices ${ }^{7}$

$$
\mathbf{w}=\mathbf{S}\left(\mathbf{p}_{1 \mathrm{~T}}\right)
$$

If, in addition, it were possible to link factor contents with product prices $\mathbf{p}_{1 \mathrm{~T}}=\mathrm{g}\left(\mathbf{A}_{\mathrm{T}} \mathbf{T}\right)$, this would establish a connection between factor contents and factor costs

$$
\mathbf{w}=\mathrm{S}\left(\mathbf{p}_{1 \mathrm{~T}}\right)=\mathrm{S}\left(\mathrm{g}\left(\mathbf{A}_{\mathrm{T}} \mathbf{T}\right)\right)
$$

This isn't something that can be done in a general way. These functions $\mathrm{S}$ and $\mathrm{g}$ are clearly dependent on the substitutability of inputs in production and the substitutability of goods in consumption. A result which can be derived, but only under special circumstances more fully described below, is

$$
\mathbf{w}=S\left(p_{1 T}\right)=S\left(g\left(v-A_{T} T\right)\right)
$$

which means that the factor content $\mathbf{A}_{\mathrm{T}} \mathbf{T}$ affects the economy in the same way as factor emigration that reduces $\mathbf{v}$. From such a restriction one would like to jump to the conclusion that if the import of labor services embodied in trade is a small share of total labor supply, then trade cannot have much affected labor. That conclusion seem plausible but it requires two additional assumptions. First it must be assumed that the autarchic factor demand functions $w=S(g(v)$ are not too inelastic, and second that the vector mapping of $\mathbf{v}$ into $\mathbf{w}$ can be decomposed into a set of scalar mappings, meaning, for example, that abundance of land does not affect the share of labor.

A lot of clarity about these points will come from two specific examples, fixed budget shares (Cobb-Douglas technologies and tastes) or fixed input ratios (Leontief technologies).

\footnotetext{
${ }^{7}$ This function can be locally defined by differentiating the zero profit conditions applicable to produced tradables to obtain

$\left(\partial \mathbf{A}_{1 T^{\prime}}\right) \mathbf{w}+\mathbf{A}_{1 \mathrm{~T}} \partial \mathbf{w}=\partial \mathbf{p}_{1 \mathrm{~T}}$.

Cost minimization implies $\left(\partial \mathbf{A}_{\mathrm{IT}}{ }^{\prime}\right) \mathbf{w}=\mathbf{0}$, which leaves the system of equations linking changes in product prices (globalization) with changes in wages:

$$
\mathbf{A}_{1 \mathrm{~T}}{ }^{\prime} \partial \mathbf{w}=\partial \mathbf{p}_{1 \mathrm{~T}}
$$
}

If this system is invertible, it defines the local Stolper-Samuelson mapping of product prices into factor prices:

$$
\partial \mathbf{w}=\left(\mathbf{A}_{1 \mathrm{~T}}\right)^{-1} \partial \mathbf{p}_{1}
$$




\subsection{COBB-DOUGLAS PRODUCTION AND COBB-DOUGLAS UTILITY}

\section{Cobb-Douglas Economy: Fully diversified, all goods traded.}

The connection between changes in the factor content of trade AT and changes in product prices p depend on technologies and tastes. The special case explored by Deardorff and Staiger(1988) is a CobbDouglas economy with all goods produced and all goods tradable. The algebra of this kind of model requires some additional definitions:

$$
\begin{aligned}
& \gamma=\text { vector of fixed consumption shares, } \mathbf{1}^{\prime} \gamma=1 \\
& \Theta=\text { matrix of fixed input shares, (factors by commodities), } \mathbf{1}^{\prime} \Theta=\mathbf{1}^{\prime} \\
& \mathbf{P}=\operatorname{diag}\{\mathbf{p}\}=\text { diagonal matrix with product prices down the diagonal } \\
& \mathbf{W}=\operatorname{diag}\{\mathbf{w}\}=\operatorname{diagonal} \text { matrix with factor prices down the diagonal }
\end{aligned}
$$

From these definitions we have

Factor Intensity Matrix

$$
A=W^{-1} \Theta P
$$

Consumption Vector

$$
P c=\gamma \quad y
$$

Factor Content of Trade

$$
F=A q-A c=v-W^{-1} \Theta P c=v-W^{-1} \Theta \gamma \quad y
$$

With no trade, $\mathbf{F}=\mathbf{0}$, this last equation determines the earnings shares in a closed (Autarchic) economy

$$
s^{A} \equiv W^{A} v / y^{A}=\Theta \gamma
$$

With this definition, the factor content becomes

$$
F=v-W^{-1} s^{A} y
$$

The corresponding earnings shares of the open economy are

$$
s \equiv W v / w^{\prime} v=(W v / y)\left(y / w^{\prime} v\right)=(W v / y) D
$$

where the deficit ratio $D$ is the ratio of expenditures to earnings, $D=y / w^{\prime} v$. With these definitions we may rewrite (4) as

$$
F_{k}=v_{k}-s_{k}^{A} y / w_{k}=v_{k}\left(1-s_{k}^{A} y / v_{k} w_{k}\right)=v_{k}\left(1-s_{k}^{A} D / s_{k}\right)
$$

For now let us assume trade balance, $\mathrm{D}=1$. Then after rearranging we have

$$
F_{k} / v_{k}=1-s_{k}^{A} / s_{k}=\left(s_{k}-s_{k}^{A}\right) / s_{k}
$$

This is a remarkable result which does fully justify the use of factor contents as an indicator of the impact of international trade on the factor markets. In words, the percentage change in the earnings share of a factor that would come from prohibitive trade barriers applied in a Cobb-Douglas economy is equal to the share of the factor that is embodied in trade. There is a very simple way to summarize this result: in a Cobb-Douglas economy, earnings shares are fixed. This means that labor's share doesn't depend on either the supply of capital or the capital services embodied in trade, or any other factor. It also means that labor's share doesn't depend on the supply of labor, whether locally or through imports of labor services. 
Thus $F_{k} / v_{k}$ is the share of labor coming from foreign sources and it is equal to the share of labor's fixed total share that must be paid to foreign workers, leaving less for domestic workers.

Although equation (5) is promising, keep in mind that there are four different questions that might be asked:

Question 1: "What effect would prohibitive trade barriers have on factor shares?"

This question is answered by the factor content calculation under the assumptions that lead to equation (5). Then, if the factor content of trade of unskilled workers is a small share of domestic supply, prohibitive trade barriers would not much affect the share of earnings of unskilled workers.

Question 2: "What effect would prohibitive trade barriers have on factor earnings?"

This question is not answered by the factor content numbers. Prohibitive trade barriers lower total real income as well as redistribute it. If the factor content of unskilled labor is negative, then prohibitive trade barriers would imply a larger share of a smaller pie, possibly so much shrunken that unskilled labor is worse off.

Question 3: "Are there selective trade barriers applied to imports of labor intensive goods that would substantially increase the earnings of unskilled workers?"

This question is not answered by the factor contents. Even if the net labor content of trade is zero, there are still trade barriers that can be used to increase the wage rate, provided that the factor contents of other inputs are not zero. The design of such trade barriers is not a trivial matter since the mapping of product prices into factor returns is complex in high-dimensional cases, and since the range of price variability that can be accomplished by trade barriers is limited in a complex way.

Question 4: "What portion of the trend in relative earnings of skilled and unskilled workers can be attributed to 'globalization'?"

This question also is not answered by the factor contents since, according to (5), changes in the factor contents as a share of domestic supply can come from changes in externally determined product prices (i.e. "globalization"), changes in tastes, $\gamma$, and changes in technology, $\Theta$, the latter two items determining the autarchic factor shares $\mathrm{s}^{\mathrm{A}}$.

\section{Trade Deficit}

What about a trade deficit, such as the US external deficit in the 1980's? How does this influence the calculation? A trade deficit that increases expenditures $y$ beyond the level of earnings does alter the factor content of trade, but the deficit need have no effect on factor earnings since product prices can be held fixed. This is straightforwardly an implication of the more general result allowing for the deficit ratio D to differ from one:

$$
F_{k} / v_{k}=1-s_{k}^{A} D / s_{k}=\left(s_{k}-D s_{k}^{A}\right) / s_{k}
$$


Now it is unfortunate that $F_{k} / v_{k}$ tells nothing about the relationships between open- and autarchic- factor shares because there is an intervening variable, the deficit ratio $D$. For example, the increased imports of labor services during the deficit period of the second half of the 1980's need have no implications for the US wage rate. This observation is reminiscent of the Leontief paradox which is also closely associated with the way the US trade surplus was treated. In Leontief's 1947 data the US was running a large trade surplus and was exporting the services of both capital and labor. A question that might have been asked is the direction of the trade in factor services if there had been no surplus. Implicit in Leontief's calculation of the factor contents of $\$ 1 \mathrm{~m}$ of exports and $\$ 1 \mathrm{~m}$ of imports is the assumption that the commodity composition of trade doesn't depend on the surplus, which is clearly not the case since with relative product prices fixed the surplus alters only consumption and not production levels, thus altering the commodity composition of trade.

We can eliminate the effect of the deficit by referring to pairs of factors in the following way

$$
\begin{aligned}
& \left(1-F_{k} / v_{k}\right) s_{k} / s_{k}^{A}=D=\left(1-F_{j} / v_{j}\right) s_{j} / s_{j}^{A} \\
& \left(1-F_{k} / v_{k}\right) /\left(1-F_{j} / v_{j}\right)=\left(s_{j} / s_{j}^{A}\right) /\left(s_{k} / s_{k}^{A}\right) \\
& \left(\frac{v_{k}-F_{k}}{v_{k}}\right) /\left(\frac{v_{j}-F_{j}}{v_{j}}\right)=\left(s_{k}^{A} / s_{k}\right) /\left(s_{j}^{A} / s_{j}\right)
\end{aligned}
$$

This last expression means that even if there is a deficit, the factor with the smallest factor content as a share of domestic supply is the one that stands to be affected least by closing down external trade. Comparisons are possible; even if absolute statements are not.

\section{Cobb-Douglas Production and Preferences. Fully diversified tradables, nontradables}

Using one special model of international commerce, the factor contents have been shown to be useful for answering only one of several questions: "What would be the impact of prohibitive trade barriers on factor shares?" Next we need to know if this conclusion about the (limited) value of the factor contents holds if the model is altered to include nontraded goods and noncompeting imports. One suspects that both of these matter. Shifts in demand for nontraded goods associated with a trade deficit, for example, are likely to alter the allocation of factors between tradables and nontradables and thus to affect the factor content of trade without changing relative prices and thus leaving factor prices unchanged. Changes in prices of noncompeting imports are similar in affecting external trade but not altering the product prices that determine factor prices. The big surprise now to be demonstrated is that with log-linearity (CobbDouglas) everywhere in sight, neither nontraded goods nor noncompeting imports matter at all, at least not in a formal mathematical sense. However, if a deficit generates a shift in favor of nontraded goods, then there is yet another interfering influence that makes it difficult to interpret factor contents.

First include in the model the nontraded goods. The factors available for the traded goods sector can then be written as

$$
\mathrm{v}_{\mathrm{T}}=\mathrm{v}-\mathrm{A}_{\mathrm{N}} \mathrm{q}_{\mathrm{N}}=\mathrm{v}-W^{-1} \Theta_{N} P_{N} \mathrm{q}_{\mathrm{N}}=\mathrm{v}-W^{-1} \Theta_{N} \gamma_{N} y
$$


where $v$ is the total factor supply. Now the factor content of trade is

$$
F=A_{T} q_{T}-A_{T} c_{T}=v_{T}-W^{-1} \Theta_{T} P_{T} c_{T}=v-W^{-1}\left(\Theta_{T} \gamma_{T}+\Theta_{N} \gamma_{N}\right) y
$$

It is something of a surprise that this equation is virtually identical to equation (4). Indeed the basic condition (6) is completely unchanged if the autarchic shares are defined by:

$$
\mathrm{s}^{\mathrm{A}}=\mathrm{Wv}^{*} / \mathrm{y}=\left(\Theta \gamma+\Theta_{N} \gamma_{N}\right) \text {. }
$$

Thus the inclusion of nontraded goods has no apparent effect on the conclusion that factor contents reveal the impacts of prohibitive trade barriers. But in this model with nontraded goods there is now another way for a trade deficit to matter. A trade deficit can and often does finance expenditures especially on nontraded goods. This means that the expenditure share of nontradables will rise and the expenditure share of tradables will fall. Thus in equation (6), a move toward autarchy changes D to one and changes $\mathrm{s}^{\mathrm{A}}$ to some new value. Now even the relative comparison suggested by Equation (7) is inappropriate.

\section{Cobb-Douglas Production and Preferences. Noncompeting imports. Nontradables}

Next we can add to the model noncompeting imports by allowing specialization of production on a subset of tradables. This will probably make a difference because lower prices of noncompeting imports should alter the factor content but have no effect on factor prices. As it turns out, however, we can add noncompeting imports to this loglinear model without making fundamental changes to it, provided that the factor contents of noncompeting imports are computed using the input intensities that would have been used had they been produced at home, a point made by Wood(1994). Thus Cobb-Douglas technologies can justify Wood's adjustments for noncompeting imports. However an entirely different treatment is needed if input intensities are fixed, the case next to be considered.

The simplest model with noncompeting imports has two factors ( $\mathrm{K}$ and $\mathrm{L}$ ), many goods but only two produced at home: one exportable and one nontradable, the later produced with labor only. With loglinear production and consumption, the real wage in such an economy is

$$
w / p_{X}=T F P_{X}(K / L)^{1-\varphi}\left(1+\frac{(1+d) \gamma_{N}}{\gamma\left(1-\gamma_{N}\right)}\right)^{1-\varphi}
$$

where $\mathrm{X}$ is the exportable, $\mathrm{K}$ and $\mathrm{L}$ are capital and labor of the economy, $\phi$ is labor's share in the exportable sector, $\mathrm{TFP}_{\mathrm{X}}$ is total factor productivity in exportables and $\gamma_{\mathrm{N}}$ is the consumption share of nontradables, $d$ is the ratio of the external deficit to GDP. This equation suggests that the connection between factor contents and wages is remote if it exists at all. Wages are simply proportional to the price of the exportable. Changes in the price of the importable which presumably alters the factor content of trade would leave nominal wages completely unchanged. It has to be a surprise therefore that the basic connection between factor contents and wages applies even in this case. The factor content of trade with some goods not produced and some nontraded goods can be written as 


$$
\begin{aligned}
& F=\left[\begin{array}{ll}
A_{T 1} & A_{T 2}
\end{array}\right]\left[\begin{array}{c}
q_{T 1} \\
0
\end{array}\right]-A_{T} c_{T}=v_{T}-W^{-1} \Theta_{T} P_{T} c_{T}=v_{T}-W^{-1} \Theta_{T} \gamma_{T} \quad y \\
& =v-W^{-1}\left(\Theta_{T} \gamma_{T}+\Theta_{N} \gamma_{N}\right) y
\end{aligned}
$$

This expression is getting to be distressingly familiar. It is exactly the same as (4). Thus, contrary to the apparent implication of (8), the inclusion of both nontraded goods and noncompeting imports has no material effect on the conclusion that factor contents reveal the effect of prohibitive trade

barriers. How can this be? Why don't lower prices for noncompeting imports increase imports and change the factor contents of trade but have no effect on factor prices? The strange answer is that the fall in the price of noncompeting imports causes a kind of technological change (the input intensities A change) which leaves the factor content unchanged. The lower price of noncompeting imports does stimulate a proportional increase in quantities consumed of noncompeting imports increase to keep the expenditure shares constant. This, you might imagine, would have an impact on the factor content of trade. But this potential impact is exactly offset by a change in the matrix of input intensities $A=W^{-1} \Theta P$, which reduces the inputs per unit of output for noncompeting imports by an amount proportional to the reduction in product prices! Thus the factor content of trade doesn't depend on the prices of noncompeting imports!! Watch out; this result only applies in a log-linear world.

As Adrian Wood (1994) observes, most factor content calculations make an aggregation error by adding non-competing imports to the corresponding domestic categories. In effect they evaluate the factor content of noncompeting imports using the corresponding domestic input intensities. An equation that helps to think about this possibility uses the domestic input intensities to evaluate noncompeting imports. Let the subscripts 1 and 2 indicate, respectively, the commodities that are produced and imports, possibly with some overlap. Suppose further, as is always the case, that the commodity aggregation schemes exactly match internally and externally. Then if we evaluate the factor content of imports of commodities 2 with the commodity 1 technology we obtain

$$
A_{1}\left(q_{1}-c_{1}-c_{2}\right)=v-A_{1} c_{1}-A_{1} c_{2}=v-W^{-1} \Theta_{1} P_{1}\left(c_{1}+c_{2}\right)=v-W^{-1} \Theta_{1}\left(\gamma_{1}+P_{1} P_{2}^{-1} \gamma_{2}\right) y
$$

Notice that this factor content calculation depends on the relative prices of domestic products relative to corresponding imports, $P_{1} P_{2}^{-1}$. If these products are identical, then the price ratio is one. But if they are not, that is to say if there are noncompeting imports, then the relative price of home goods compared to the corresponding noncompeting imports affects the factor contents, even though reduction in $\mathrm{P}_{2}$ holding fixed $P_{1}$ leaves domestic nominal factor prices unchanged. The message here is that we ought to be evaluating noncompeting imports at the factor intensities that would have been used had the goods been made at home, which is exactly what Wood(1994) argues. But be careful, as is now to be shown, if the input intensities A are fixed, a very different treatment is required. 


\subsection{FIXED-INPUT INTENSITIES, COBB-DOUGLAS PREFERENCES}

\section{Fixed Input Technologies. Equal numbers of Tradables and Factors}

The feature that drives the results applicable to log-linear technologies is an input intensity matrix A that depends on product prices. The usefulness of factor contents is distinctly less if we abandon the Cobb-Douglas assumption in favor of the assumption that the input intensities $\mathbf{A}$ are fixed. With all goods traded and produced, the factor content is then

$$
A T=A q-A c=v-A P^{-1} P c=v-A P^{-1} \gamma \quad y
$$

Here there is no simple relationship between the factor contents and the factor returns. At issue is whether we can back out of data on factor contents the difference between world equilibrium prices and autarchy prices and then use the Stolper-Samuelson mapping applicable to the even model, $w=A^{\gamma-1} p$, to solve for the factor prices $w$ as functions of the goods price $p$. The mapping from factor supplies into prices can be found by manipulating the previous expression

$$
\begin{aligned}
& P A^{-1}(v-F)=\gamma \quad y \\
& p / y=\gamma\left[\operatorname{diag}\left\{A^{-1}(v-F)\right\}\right]^{-1}
\end{aligned}
$$

Then use the Stolper-Samuelson mapping $w=A^{,-1} p$ to obtain

$$
w / y=A^{\prime-1} p / y=A^{1-1} \gamma\left[\operatorname{diag}\left\{A^{-1}(v-F)\right\}\right]^{-1} .
$$

This defines a mapping of $\mathbf{v}-\mathbf{F}$ into factor prices relative to domestic expenditures, $w / y$. It is a complex vector mapping which is not decomposable into a set of scalar functions. It therefore does not allow one to make claims such as the one applicable to the Cobb-Douglas economy that a small value of the factor content of one factor relative to its total supply means that this factor would be little affected by economic isolation.. There is something that can be said. The factor content $\mathbf{F}$ is like an increase in the factor supply in the closed economy, a feature that is implied by the form of the mapping which depends on $\mathbf{v - F}$, and which can be summarized by the equation

$$
\mathbf{w}=\mathbf{g}(\mathbf{v}-\mathbf{F}) \mathbf{p}^{\prime} \mathbf{c}=\mathbf{g}(\mathbf{v}-\mathbf{F}) \text { GDP } \quad D
$$

where GDP is the value of output, $D$ is the deficit ratio, and $\mathbf{g}$ is a vector of functions. The closed economy mapping of factor supplies into factor rewards comes from this equation with $\mathbf{F}=\mathbf{0}$, and $\mathbf{D}=1$, namely $\mathbf{w}=\mathbf{g}(\mathbf{v})$ GDP. Thus the open economy with balanced trade behaves like the closed economy with factor supplies equal to v-F. This condition earns a box since it is the fundamental result applicable to fixed input technologies, analogous to (6) which applies to Cobb-Douglas technologies. Indeed (9) applies under broader assumptions. For an open economy to behave like a closed economy with altered factor supplies it is necessary that trade and migration be perfect substitutes. This requires that all goods are produced, a condition which is discussed more below. 


\section{Fixed Input Technologies. Equal numbers of Tradables and Factors. Nontradables}

As in the Cobb-Douglas case, it is not difficult to add to the model a nontradable sector. The factors remaining for production of tradables after satisfying the demand in nontradables is

$$
\mathrm{v}_{\mathrm{T}}=\mathrm{v}-\mathrm{A}_{\mathrm{N}} \mathrm{q}_{\mathrm{N}}=\mathrm{v}-A_{N} P_{N}^{-1} \gamma_{N} y
$$

Then the factor content of trade is

$$
F=A_{T} q_{T}-A_{T} c_{T}=v_{T}-A_{T} P_{T}^{-1} \gamma_{T} y=v-A_{N} P_{N}^{-1} \gamma_{N} y-A_{T} P_{T}^{-1} \gamma_{T} y
$$

With equal numbers of tradables and factors, the mapping from product prices into factor rewards and prices of nontradables are

$$
\begin{aligned}
& w=A_{T}{ }^{1-1} p_{T} \\
& p_{N}=A_{N}{ }^{\prime} w=A_{N}{ }^{\prime} A_{T}{ }^{1-1} p_{T}
\end{aligned}
$$

The second set of equations allows us to replace the prices of nontradables in (10) with the prices of tradables. The system (10) then defines a mapping from prices of tradables into factor contents (10). Provided this is invertible, which requires at least that the number of factors is less than or equal to the number of tradables, we can solve for the prices of tradables from the factor contents. Then these prices can be inserted into the first set of equations to find the corresponding factor prices, thus linking factor contents $(\mathrm{F}-\mathrm{v}) / \mathrm{y}$ to factor prices. Thus: the factor content of trade is like an increase in the factors of a closed economy, even if there are nontradables, although, as above, an external deficit might alter the share of expenditure on nontradables and thus affecting the factor content of trade and intervening in the simple interpretation suggested by (9).

\section{Fixed-Input Intensities, Noncompeting imports. Equal numbers of Tradables and Factors. nontradables}

A very different conclusion arises if production specializes on a subset of tradables since the prices of noncompeting imports affects the factor contents. The factor content is then

$$
\begin{aligned}
& F=A_{T} q_{T}-A_{T} c_{T}=v_{T}-A_{T} P_{T}^{-1} \gamma_{T} y=v-A_{N} P_{N}^{-1} \gamma_{N} y-A_{T} P_{T}^{-1} \gamma_{T} y \\
& =v-A_{N} P_{N}^{-1} \gamma_{N} y-A_{T 1} P_{T 1}^{-1} \gamma_{1 T} y-A_{72} P_{T 2}^{-1} \gamma_{T 2} y
\end{aligned}
$$

With the number of tradables produced equal to the number of factors, we can use the standard mapping of the tradables prices into factor costs and into nontradables prices

$$
\begin{aligned}
& w=A_{T 1}{ }^{{ }^{-1}} p_{T 1} \\
& p_{N}=A_{N}{ }^{\prime} w=A_{N}{ }^{\prime} A_{T}{ }^{1-1} p_{T 1}
\end{aligned}
$$

We can use this last condition to eliminate the price of nontradables from the factor contents, but there is no way to eliminate the prices of noncompeting imports. These prices do not affect wages and there will consequently be changes in the factor contents that do not have any implications for factor costs. Thus if there are noncompeting imports and technologies have fixed input ratios, the relationship between factor contents and factor rewards is broken since it depends also on the prices of noncompeting imports. Using the correct input intensities to evaluate the factors embodied in noncompeting imports works for Cobb-Douglas technologies, but not for fixed input technologies. 
These noncompeting imports create a dual labor market with some imported labor not competing for the same jobs as domestic workers. Another treatment might attempt to compute factor contents only for competing imports. (Empirically, this would be a terrible task.) Excluding noncompeting imports, the factor content of trade is

$$
F_{1}=A_{T 1} q_{T 1}-A_{T 1} c_{T 1}=v_{T}-A_{T 1} P_{T 1}^{-1} \gamma_{T 1} y=v-A_{N} P_{N}^{-1} \gamma_{N} y-A_{T 1} P_{T 1}^{-1} \gamma_{T 1} y
$$

If factor prices are determined by external competitiveness conditions (11), both the prices of tradables and the prices of nontradables in this expression can be replaced with suitable functions of the factor costs w. Thus analogous to the argument following (10) we are lead to condition (9). In words, the factor content of trade in competing products has the same effect on wages as the emigration of factors, provided that this emigration doesn't alter the product mix. It is distinctly not the case that we can replicate the open economy equilibrium with a closed economy employing suitably selected factor supplies.

\section{Fixed-Input Intensities. Number of tradables less than the number of factors, nontradables}

As a final coup de'gras, there is another equilibrium in which the number of tradables produced is not enough to define fully the Stolper-Samuelson mapping of the prices of tradables into the factor prices. While the zero profit conditions are still applicable,

$$
\begin{aligned}
& p_{T 1}=A_{T 1}{ }^{\prime} w \\
& p_{N}=A_{N}{ }^{\prime} w
\end{aligned}
$$

there are not enough tradables to invert the external zero profit conditions to solve for internal factor prices w. Then factor prices are partly determined by external competitiveness conditions and partly by internal local demand for nontradables. For this case, trade is not equivalent to a change in factor supplies for a closed economy because the international equilibrium selects specialization patterns that are unavailable to the closed economy. 


\section{Selected References}

Baldwin, Robert E. (1995), "The Effect of Trade and Foreign Direct Investment on Employment and Relative Wages, NBER Working Paper No. 5037.

Bhagwati, Jagdish (1995), "Trade and Wages: Alternative Theoretical Approaches", manuscript.

Bowen, H., Edward E. Leamer and Leo Sveikauskus (1987), "Multicountry, Multifactor Tests of the Factor Abundance Theory," American Economic Review, December 1987, 77, 791-809.

Dixit, A.K. and V. Norman (1980), Theory of International Trade (Cambridge University Press, London).

Deardorff , A. and Dalia Hakura (1993), "Trade and Wages: What are the Questions," in Bhagwati, Jagdish and Marvin H. Kosters, eds., Trade and Wages, Washington, D.C.: AEI Press, 76-107.

Deardorff, A. and Staiger, R. (1988), "An Interpretation of the Factor Content of Trade," Journal of International Economics, 24, 93-107.

Katz, Lawrence F. and Kevin Murphy (1992), "Changes in Relative Wages, 1963-1987: Supply and Demand Factors," Quarterly Journal of Economics, CVII, February, 36-78.

Krugman, Paul (1995) "Technology, Trade and Factor Prices," NBER Working Paper 5355.

Krugman, Paul and Robert Lawrence (1993), “Trade and US Wages,” NBER Working Paper No. 4478.

Lawrence, Robert Z. and Matthew J. Slaughter (1993), "International Trade and American Wages in the 1980s:: Giant Sucking Sound or Small Hiccup?”, Brookings Papers on Economic Activity, 2, 1993,pp 161-226.

Leamer, Edward E. (1980) ,"The Leontief Paradox, Reconsidered," The Journal of Political Economy, Vol 88, No. 3, June, 495-503.

Leamer, Edward E. (1993), "US Wages and a US-Mexican Free Trade Agreement," ....

Leamer, Edward E. (1994) "Trade, Wages and Revolving Door Ideas," NBER Working Paper No. 4716, April

Leamer, Edward E. (1995), "In Search of Stolper-Samuelson Effects on US Wages," in Susan Collins, ed., Imports, Exports and the American Worker, The Brookings Institution, Washington, D.C. Brookings Volume, forthcoming.

Leontief, W. W. (1953), "Domestic Production and Foreign Trade: The American Capital Position Reexamined," Proceedings of the American Philosophical Society, 97, 332-349.

Leontief, W. W. (1956), "Factor Proportions and the Structure of American Trade," The Review of Economics and Statistics, , 386-407.

Murphy, Kevin and Finis Welch (1991), "The Role of International Trade in Wage Differentials," in M.Kosters (ed.) Workers and Their Wages, Washington, D.C.: American Enterprise Institute.

Sachs, Jeffrey D. and Howard J. Shatz (1994), "Trade and Jobs in U.S. Manufacturing," Brookings Papers on Economic Activity, 1, 1994, pp 1-84.

Wood, Adrian (1994), North-South Trade, Employment and Inequality, Changing Fortunes in a SkillDriven World, Oxford: Clarendon. 